\title{
ANÁLISE DOS TEORES DE ARSÊNIO NA ÁREA DE CONFLUÊNCIA DOS RIOS PIRANHAS E SERIDÓ - RN
}

Mário Tavares de Oliveira Cavalcanti Neto ${ }^{1}$ Bruna Marcela Soares de Araújo² Luiz Fernando Dias Filho ${ }^{3}$

Resumo: Esta pesquisa teve como foco principal a análise de Arsênio em sedimentos de corrente, solos e rochas em uma área na confluência dos rios Piranhas e Seridó, no Estado do Rio Grande do Norte. A metodologia de coleta e preparação das amostras para análise seguiu critérios internacionais de Qualidade (QA/QC) e foi realizada em conjunto com a empresa canadense Eldorado Gold Corporation, através de suas subsidiárias brasileiras. O Arsênio está presente em concentrações acima dos valores de referência, numa área que se situa a montante da barragem de Oiticica, em construção, que terá uma capacidade prevista de mais de 550 milhões de metros cúbicos de armazenamento de água. O uso desta água será para o abastecimento que atenderá a uma parcela significativa da população do semiárido potiguar, onde vivem mais de cem mil pessoas considerando apenas os municípios diretamente afetados.

Palavras-chave: Arsênio. Contaminação. Rios Piranhas e Seridó. Ouro. Amostragem

\section{ANALYSIS OF ARSENIC CONTENTS IN THE CONFLUENCE AREA OF RIOS PIRANHAS AND SERIDO - RN}

Abstract: This research was mainly focused on performing analysis of arsenic in stream sediments, soils and rocks in an area at the confluence of Piranhas and Seridó Rivers in Rio Grande do Norte state, northeast of Brazil. The methodology of collecting and preparing samples for analysis followed international standards of quality (QA / QC) and was carried out in conjunction with the Canadian Company Eldorado Gold Corp., through its Brazilian subsidiaries. Arsenic is present in concentrations above reference values in an area that is located upstream of the Oiticica Dam, which is under construction and has a storage capacity of $556 \mathrm{x}$ $10^{6} / \mathrm{m}^{3}$, and will supply a large portion of the population from the State semiarid region where live more than one hundred thousand people, considering only municipalities directly affected.

Keywords: Arsenic. Contamination. Piranhas and Seridó Rivers. Gold. Sampling.

\section{ANÁLISIS DE LOS TEORES DE ARSENIO EN EL ÁREA DE CONFLICUACIÓN DE LOS RÍOS PIRANHAS Y SERIDÓ - RN}

Resumen: Esta investigación tuvo como objetivo principal, el análisis de arsénico en sedimentos fluviales, suelo y rocas en el área de la afluencia de los ríos Piranhas y Seridó, en el estado de Rio Grande do Norte. La metodología de recolección y preparación de las muestras para análisis siguió criterios internacionales de Calidad (QA / QC) y fue realizada en conjunto con la empresa canadiense Eldorado Gold Corporation, a través de sus subsidiarias brasileñas. Los resultados nos muestran

\footnotetext{
${ }^{1}$ IFRN, PPgUSRN, Natal, Brasil, mario.tavares@ifrn.edu.br, https://orcid.org/0000-0002-9248-3382

${ }^{2}$ IFRN, DIAREN, Natal, Brasil, bruna.araujo@ifrn.edu.br, https://orcid.org/0000-0003-3593-7592

${ }^{3}$ IFRN, DIAREN, Natal, Brasil, Ifdfilho@gmail.com, https://orcid.org/0000-0003-4700-3797
} 
que el Arsénico está presente en concentraciones por encima de los valores de referencia, en un área que se sitúa por encima de la represa de Oiticica, en construcción, que tendrá una capacidad prevista de más de 550 millones de metros cúbicos de almacenamiento de agua. El uso del agua será para el abastecimiento que atenderá a una parte significativa de la población del semiárido potiguar, donde viven más de cien mil personas considerando solo los municipios directamente afectados.

Palabras clave: Arsénico. Contaminación. Ríos Piranhas y Seridó. Oro. Muestreo.

\section{Introdução}

$\mathrm{Na}$ área de confluência dos rios Piranhas e Seridó, entre os municípios de Timbaúba dos Batistas, Caicó, Jardim de Piranhas e São Fernando, no Estado do Rio Grande do Norte, ocorre geologicamente uma zona de cisalhamento mineralizada em Ouro ( $\mathrm{Au}$ ), de mais de $40 \mathrm{Km}$ de comprimento. Essa faixa foi intensamente explorada por garimpeiros entre os anos de 1950 e 1980 tendo, posteriormente, episódios intermitentes de produção de ouro até os dias de hoje, na dependência do preço desta comodity e das oportunidades de obtenção de renda do sertanejo. Os principais garimpos, são: Ponta de Serra, Anastácio, Tapera, Simpático, Caifás, Serra dos Patos e Serra dos Rodrigues. A exploração sempre foi predominantemente artesanal, conforme definição do Banco Mundial (2011), caracterizada pelo uso de máquinas, equipamentos e tecnologias de extração e beneficiamento rudimentares e do tipo garimpeira, ou seja, desconsiderando os trabalhos de pesquisa mineral anteriores à produção, de acordo com o que define a Lei no 7805 de 10/07/1989 (BRASIL, 1989).

O ouro explorado nesses garimpos está hospedado em veios e filões de quartzo, em sillimanita muscovita quartzo gnaisse, em sericita quartzo xisto e em metatonalitos. O ouro ocorre associado ao mineral arsenopirita, um sulfeto de Ferro e Arsênio (FeAsS) que contem $46 \%$ de Arsênio (As), $19,7 \%$ de S e 34,3\% de Ferro (Fe) (UNESP, 2015). Na superfície, o enxofre presente nesta fase mineral foi naturalmente lixiviado, deixando o ouro livre e visível a olho nu. O mesmo não acontece em subsuperfície, onde o sulfeto está preservado dos agentes intempéricos naturais e o ouro está presente na estrutura do mineral arsenopirita, sendo invisível a olho nu, razão pela qual os garimpeiros não aprofundaram suas explorações, deixando uma reserva mineral remanescente.

O Arsênio, naturalmente lixiviado foi carreado pelos agentes erosivos naturais, contaminando a rede de drenagem que atravessa a faixa mineralizada e o solo proximal dos garimpos mencionados anteriormente. Considera-se, apesar da 
necessidade de uma análise mais aprofundada, que a vegetação sobre esses solos contaminados e os animais que se alimentam destas plantas assim como toda a cadeia alimentar estejam sujeitos a níveis elevados de As. O Arsênio é o elemento mais perigoso à saúde humana, segundo lista de substâncias perigosas da Comprehensive Environmental Response, Compensation and Liability Act CERCLA (ATSDR, 2014) pois é uma substância carcinogênica que se apresenta de várias formas, sendo a inorgânica, como esta proveniente da arsenopirita dos garimpos abordados neste trabalho, a mais nociva ao homem (FIGUEIREDO et al., 2006).

Segundo Figueiredo et al. (2006) a via mais comum de exposição humana é através do consumo de água contaminada devido a dispersão do metal pela rede de drenagem, como por exemplo o que ocorre na zona de confluência dos Rios Piranhas e Seridó na sua zona de confluência. 
Figura 1-Mapa de Localização da área estudada e das estações de coleta de amostras de sedimento de corrente.
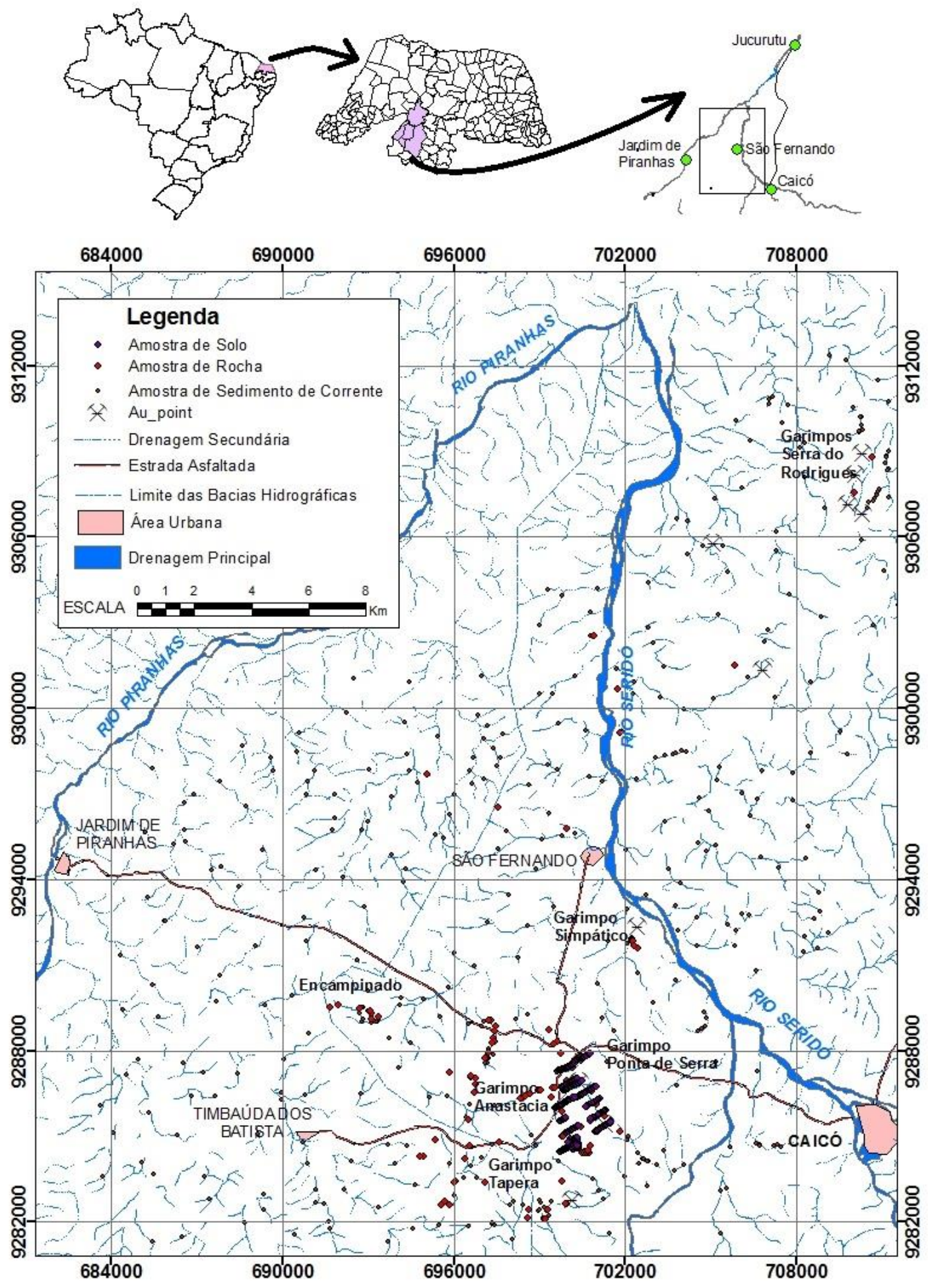

Fonte: CAVALCANTI NETO (2012, p. 39).

A área de estudo localiza-se em um peneplano, com "inselbergs" que se destacam no relevo e os solos são caracterizados por ser de pequena profundidade (menos de 1 metro). 
A população residente, na área de entorno, é de 100.313 habitantes, segundo estimativa do IBGE (BRASIL, 2014), sendo a menor a de Timbaúba dos Batista com 2.408 habitantes e a maior a do município de Caicó com 62.709 residentes.

Comparativamente, o município de Caicó apresenta melhores indicadores socioeconômicos e condições infraestruturais. O Índice de Desenvolvimento Humano Municipal (IDHM), segundo BRASIL (2014) considerado alto $(0,710)$, entre os quatro primeiros do Estado do Rio Grande do Norte. Já o seu Índice de Gini, que representa a desigualdade social $(0,47)$ (BRASIL, 2014), apresentou uma melhora significativa em relação à última medição $(0,56)$. Isso se deve, às políticas de inclusão social do governo federal na última década, apesar da Incidência de Pobreza ser ainda muito alta, alcançando alarmantes 52,62\%, (BRASIL, 2014). $\mathrm{Na}$ saúde, o município conta com 56 estabelecimentos hospitalares, dos quais 14 possuem atendimento de alguma especialidade médica. São 165 leitos para atendimento da população de 62.709 habitantes e dos residentes nos municípios vizinhos. Existem dois tomógrafos na sede municipal (DATASUS, 2009; BRASIL, 2014), equipamento que serve para o diagnóstico de câncer, malignidade que pode ser causada pelo Arsênio.

Tanto São Fernando como Timbaúba dos Batistas não contam com especialidades médicas, não existem leitos para internação e nem contam com equipamento para diagnóstico do câncer. $\mathrm{Na}$ ausência de medicina preventiva, o câncer tem sido identificado somente nos estágios mais avançados, quando os pacientes se socorrem na cidade de Caicó. Para exemplificar a incidência dessa malignidade, $50 \%$ das mortes entre as pessoas na faixa etária de 50 a 64 anos no município de São Fernando são devido ao câncer, contra uma média de cerca de 17\% em todo o Estado do Rio Grande do Norte (DATASUS, 2009). Entretanto, as relações dos casos de câncer com as anomalias de Arsênio ainda não estão comprovadas cientificamente. Os indicadores socioeconômicos e de saúde de cada município estão elencados no Quadro I.

QUADRO 1: QUADRO RESUMO DOS INDICADORES

\begin{tabular}{|lccccc|}
\hline Índices & Caicó & Jucurutu & $\begin{array}{c}\text { Jardim de } \\
\text { Piranhas }\end{array}$ & $\begin{array}{c}\text { São } \\
\text { Fernando }\end{array}$ & $\begin{array}{c}\text { Timbaúba } \\
\text { dos Batistas }\end{array}$ \\
\hline IDHM & 0,710 & 0,0303 & 0,603 & 0,608 & 0,640 \\
Gini & 0470 & 0,400 & 0,380 & 0,370 & 0,380 \\
\hline
\end{tabular}




\begin{tabular}{|l|ccccc|}
\hline $\begin{array}{l}\text { Índice de pobreza } \\
\text { (\%) }\end{array}$ & 52,62 & 53,77 & $52,62 \%$ & 49,16 & 48,55 \\
$\begin{array}{l}\text { Estabelecimentos } \\
\text { hospitalares } \\
\begin{array}{l}\text { Especialidade } \\
\text { médica }\end{array}\end{array}$ & 56 & 21 & 5 & 0 & 1 \\
$\begin{array}{l}\text { Tomógrafos } \\
\text { Leitos }\end{array}$ & 02 & 0 & 0 & 0 & 0 \\
\hline
\end{tabular}

Fonte: BRASIL (2014)

Por se tratar de uma população predominantemente pobre, com baixo nível de escolaridade e com acesso restrito às informações, identifica-se aí uma alta vulnerabilidade ao risco representado pela contaminação por Arsênio. A inexistência de uma assistência médica preventiva soma-se a esta e a outras vulnerabilidades, potencializando possíveis cenários de desastre. Adicionalmente.

A constante estiagem e os prolongados períodos de seca demandam programas de convivência com o fenômeno climático que contemplem, entre outros, o represamento das águas dos rios da região para abastecimento da população e agropecuária nos períodos de estiagem.

A barragem Governador Iberê Ferreira de Souza, ou barragem de Oiticica é um empreendimento que faz parte do Projeto Eixo de Integração do Seridó ou Plano de Recursos Hídricos do Seridó (PRHS), o qual contempla o Sistema Adutor Jardim do Seridó, Sistema Adutor Piranhas-Caicó e Sistema Adutor Serra de Santana. Esse reservatório situa-se nos municípios de Jucurutu, São Fernando e Jardim de Piranhas (MELO, 2008 p. 65-66), a jusante e adjacente à área estudada, anômala em Arsênio. Esta barragem deverá armazenar 556 milhões de metros cúbicos de água e custará $R \$ 221.500 .000,00$ (duzentos e vinte e um milhões e meio de reais) (BRASIL, 2015). O seu principal objetivo é a contenção de cheias no sentido da "redução de riscos de inundações no Vale do Açu, e a diminuição do déficit hídrico da sub-bacia do rio Seridó, a qual responde por $90 \%$ do déficit hídrico da bacia do rio Piranhas/Açu" (MELO 2008, p. 58). Com a construção de um canal de $36 \mathrm{~km}$ de extensão a partir da barragem de Oiticica, estarão interligados os açudes de Cruzeta, Passagem das Traíras e Itans, possibilitando a irrigação de 2.500 hectares (BRASIL, 2012, p. 153). As aduções e interações contemplarão mais de 500.000 habitantes, considerando $\mathrm{o}$ trecho norte-rio-grandense da Bacia Hidrográfica Piranhas-Açu (NOGUEIRA, 2006, p. 81). 
Com a construção desta barragem o poder público busca a sustentabilidade hídrica, conforme definida por Melo (2008, p. 27), como sendo aquela cujo potencial em superfície e subsuperfície é capaz de suprir todas as demandas de água, uma vez que a escassez ou improbidade de água é um fator limitante ao desenvolvimento (SILVA et al. 2002, p. 124). Dessa forma, os autores consideram diminuir os graves efeitos da seca, com base nos princípios de sustentabilidade econômica, social e ambiental.

\section{Material e Métodos}

Nesta pesquisa, a metodologia de coleta e preparação das amostras para análises foi aquela estabelecida no manual de procedimentos da empresa canadense Eldorado Gold Corp. através de suas subsidiárias brasileiras: a São Bento Mineração S/A e de sua sucedânea a Unamgen Mineração e Metalurgia S.A. Essas empresas concederam apoios financeiros ao presente estudo, os quais possibilitaram a plena realização do trabalho de campo, o transporte de amostras e as análises laboratoriais, essenciais a análise dos níveis de arsênio. A metodologia é também conhecida como método QA/QC (Assurance Control / Quality Control ou Garantia de qualidade / Controle de qualidade), o qual é baseado nas recomendações da USEPA (1995), do Serviço geológico dos Estados Unidos (USGS), contidos em Barker (1997) e Hammarstrom et al. (2003), e em práticas de coletas de instituições de pesquisas descritas por Bloom (2002), Bond (2008), normas de amostragens relacionadas pelo CETEM (apud GÓES et al. 2004), por Lins (2003) e pelas Normas N024 da Rede Metrológica de Minas Gerais (MINAS GERAIS, 2011), entre vários outros. A coleta de amostras para este estudo foi do tipo composta, ou seja, a coleta foi realizada em uma pequena área ao redor do ponto da estação de amostragem e não apenas em um local pontual. Desta forma, se obteve uma maior representatividade da área. As amostragens sistemáticas e de detalhe, no caso dos solos e de rochas, a coleta foi pontual, seguindo uma malha uniforme previamente definida em ambiente ArcGis versão 10.1 e alcançada no campo por navegação com GPS Garmim 60Csx.

Algumas amostras foram selecionadas para descrição petrográfica com 0 objetivo de identificar os minerais e confrontar com os resultados de laboratório para identificar a fonte da possível presença de metais prejudiciais à saúde humana e de interesse da empresa financiadora dos estudos. 
Ao todo foram coletadas 432 amostras de sedimentos ativos de corrente, 364 amostras de solos e 1.698 amostras de rocha. A coleta das amostras de sedimentos ativos de corrente foi feita nas drenagens secundárias que são de regime intermitente, como é típico do semiárido norte-rio-grandense, na denominada região do polígono das secas. Os locais de coleta foram preferencialmente nas confluências das drenagens e também ao longo de sua extensão, de modo que a equidistância entre as amostras não superasse $500 \mathrm{~m}$.

O procedimento de coleta foi o seguinte: uma régua de plástico foi usada para a retirada e descarte da parte da superfície composta ou influenciada por matéria orgânica e, com uma pá de plástico, às vezes com as mãos, desprovidas de quaisquer metais, se coletou, pelo menos, o volume de 1 litro do sedimento ativo de corrente. Houve um cuidado com a profundidade de coleta, uma vez que esse tipo de amostra tem a função de revelar a composição química de uma região a montante do local de coleta na bacia de captação e o aprofundamento poderá fornecer uma informação restrita ao ponto de amostragem, relativa a materiais concentrados mecanicamente pelos processos naturais (placer).

As amostras de solo foram coletadas numa área abrangendo os garimpos de Ponta de Serra, Anastácio e Tapera. Todos os horizontes pedológicos foram considerados, devido à pequena espessura do solo, típico dessa região do semiárido, onde as rochas costumam aflorar. Eliminando-se a camada de matéria orgânica, foi coletado todo o material até o nível do saprolito.

As amostras de rochas foram coletadas em duas etapas distintas: uma regional e outra em locais anômalos e/ou naqueles onde os garimpeiros haviam realizado trabalhos de extração artesanal. $\mathrm{Na}$ etapa regional foram coletadas amostras das diferentes litologias ao longo da área de interesse. Foram coletadas 226 amostras de rocha.

Amostras de rocha também foram coletadas nos garimpos de Ponta de Serra, (incluindo Tapera, Anastácia), Serra dos Rodrigues / Serra dos Patos e Simpático. As amostras de rocha foram coletadas em pedaços (chip sample), obedecendo canaletas de 15 a $20 \mathrm{~cm}$ de largura por $3 \mathrm{~cm}$ de profundidade ao longo de toda a espessura do corpo rochoso hospedeiro da mineralização aurífera.

A preparação das amostras foi realizada a partir de britagem com abertura de 1" (uma polegada), moagem e peneiramento. O processo foi realizado em circuito fechado até atingir a granulometria de 200\# (duzentos mesh). Em seguida, as amostras foram homogeneizadas e divididas da seguinte forma: uma encaminhada 
para a análise química e outra guardada como reserva técnica. Entre cada preparação, os equipamentos foram limpos para evitar contaminação.

Algumas amostras tiveram uma fração separada para concentração manual, com auxílio de uma bateia, para aumentar o teor dos metais pesados presentes na amostra em quantidades muito pequenas. Com isso a sua identificação, por equipamentos de menor precisão, seria facilitada, prestando uma contribuição suplementar à ferramenta QA/QC.

As amostras foram enviadas aos laboratórios SGS/Geosol, sito a Rodovia MG-010, Km 24,5, bairro Angicos, CEP: 33200-000, Vespasiano/MG, e ALS Chemex, situado à Brooksbank Avenue, North Vancouver no Canadá, BC V7J 2Cl. Os processos de análises seguiram as determinações do pacote comercial desses laboratórios, sendo a análise multielementar por (ICP - MS) "Inductively Coupled Plasma - Mass Spectrometre" para 32 elementos e a análise do ouro por fire assay e Absorção Atômica. Os pacotes comerciais dos laboratórios da SGS/Geosol e ALS Chemex permitem a análise dos seguintes elementos, nas unidades e limites de detecção informados a seguir: Ag, As, Ba, Be, Cd, Cr, Cu, Li, Mo, Ni, Sc, Sr, Zn, Zr, $Y$ na escala de ppm (porção por milhão) sendo o limite inferior de detecção de 1 ppm; Co, Pb, Sb, V em ppm e limite inferior de detecção de 3 ppm; Bi, Sn, W, La e B também na escala de ppm e com limite inferior de detecção de 10 ppm; e Al, Ca, Fe, $\mathrm{K}, \mathrm{Mg}, \mathrm{Mn}, \mathrm{Na}, \mathrm{P}$ e Ti na escala de percentagem com limite de detecção de 0,01\%. O Limite superior de detecção para todos os elementos mencionados é 5.000 ppm. As conversões entre as unidades de medida de teor foram realizadas seguido este exposto: $1 \mathrm{ppm}=1 \mathrm{~g} / \mathrm{ton}=1 \mathrm{mg} / \mathrm{L}=1.000 \mu \mathrm{g} / \mathrm{L}=1.000 \mathrm{ppb}=1 \mathrm{mg} / \mathrm{Kg}=0,0001 \%$.

A análise do ouro por fire assay foi do tipo quantitativa pelo qual o metal foi separado por fusão em meio redutor, dissolvido em água régia (3:1 ou seja 3 quantidades de $\mathrm{HCl}$ para uma de ácido nítrico) e o teor determinado por Absorção Atômica. O limite de detecção foi de 5 porção por bilhão (ppb), para uma alíquota de 30 gramas e de 3 ppb para uma alíquota de 50 gramas.

Os resultados das análises químicas foram tabulados no Microsoft Access e plotados no software ArcGis versão 10.1 para, então, serem gridados os teores utilizando a ferramenta "Geostatistical Analyst Tools", método de regressão "Kriging" ou Krigagem. Algumas gridagens foram feitas no software Geosoft Oasis Montaj versão 6.4.2 para comparação usando o mesmo de método de regressão. Esses resultados analíticos ainda foram comparados com os valores de referência 
estabelecidos pela CETESB (SÃO PAULO, 2012), como também por instituições como IBAMA, EPA, ATSDR e USGS, compilado da CETESB (2012).

\section{Resultados e Discussão}

Os níveis de Arsênio, na área de confluência dos rios Piranhas e Seridó, estão presentes em quantidades maiores que os valores de referência para a água (potável, doce e subterrânea).

No solo, foram encontrados valores de Arsênio acima daqueles recomendados pela CETESB (SÃO PAULO, 2005) como de referência para a qualidade do solo, mas acima também de todos os níveis, incluindo desde o nível de Prevenção àqueles sujeitos aos efluentes industriais. Foram encontradas amostras com teor acima do dobro do maior valor de referência (industrial), cujos resultados estão sumarizados na Tabela 1. No sedimento de corrente, foram encontrados 16 valores de teor de Arsênio (As) maiores que a média mais o desvio padrão $(X+\sigma)$ e três valores acima do valor de referência. Neste contexto, Cavalcanti Neto et al., (2014) fazem uma discussão sobre os teores de referência em sedimento de corrente, uma vez que não existem trabalhos sobre o tema.

Tabela 1: Síntese estatística de sedimento de corrente e solos e os valores de referência da Cetesb (SÃO PAULO, 2005) e Conama (BRASIL, 2009) para Tapera, Anastácio e Ponta de Serra.

\begin{tabular}{|c|c|c|c|c|c|c|c|c|c|}
\hline \multicolumn{5}{|c|}{$\begin{array}{c}\text { SÍNTESE ESTATÍSTICA DOS } \\
\text { DADOS ANALÍTICOS }\end{array}$} & \multicolumn{5}{|c|}{ VALORES DE REFERÉNCIA } \\
\hline Mín. & Máx & Média & $\sigma$ & $\mathrm{V}$ & VRQ & Prev. & Agrícola & Resid. & Ind. \\
\hline 0 & 301 & 3,96 & 25,11 & 634 & 3,5 & 15 & 35 & 55 & 150 \\
\hline 0 & 8 & 0,270 & 0,749 & 277 & & & & & \\
\hline
\end{tabular}

Fonte: CAVALCANTI NETO (2012).

Min = valor mínimo; Máx = Valor Máximo; $\sigma=$ Desvio Padrão;

$\mathrm{V}=$ Coeficiente de variação; $\mathbf{X}+\boldsymbol{\sigma}=$ Média + um Desvio Padrão; $\mathrm{VRQ}=$ Valor de referência de qualidade; Prev. = Prevenção; Resid. = Residência; Ind.= Indústria

Comparados com os Valores de Referência (BRASIL, 2009; SÃO PAULO, 2005), sobressalta aos olhos os elevados teores de Arsênio no solo, especialmente 
na área do garimpo de Ponta de Serra, a montante da barragem de Oiticica ainda em fase de construção.

Além disso, foram identificados teores muito acima dos valores de referência e daqueles de intervenção apontados pelo CONAMA Resolução № 420 (BRASIL, 2009) e pela CETESB (SÃO PAULO, 2005), considerando todos os efluentes abrangidos por aquela Resolução, quais sejam: agrícola, residencial e industrial, merecendo especial atenção quanto às implicações à saúde (figura 2).

Figura 2: Gráfico comparativo dos teores das amostras de solo com os valores de referência estabelecidos em BRASIL (2009) e SÃO PAULO (2005).

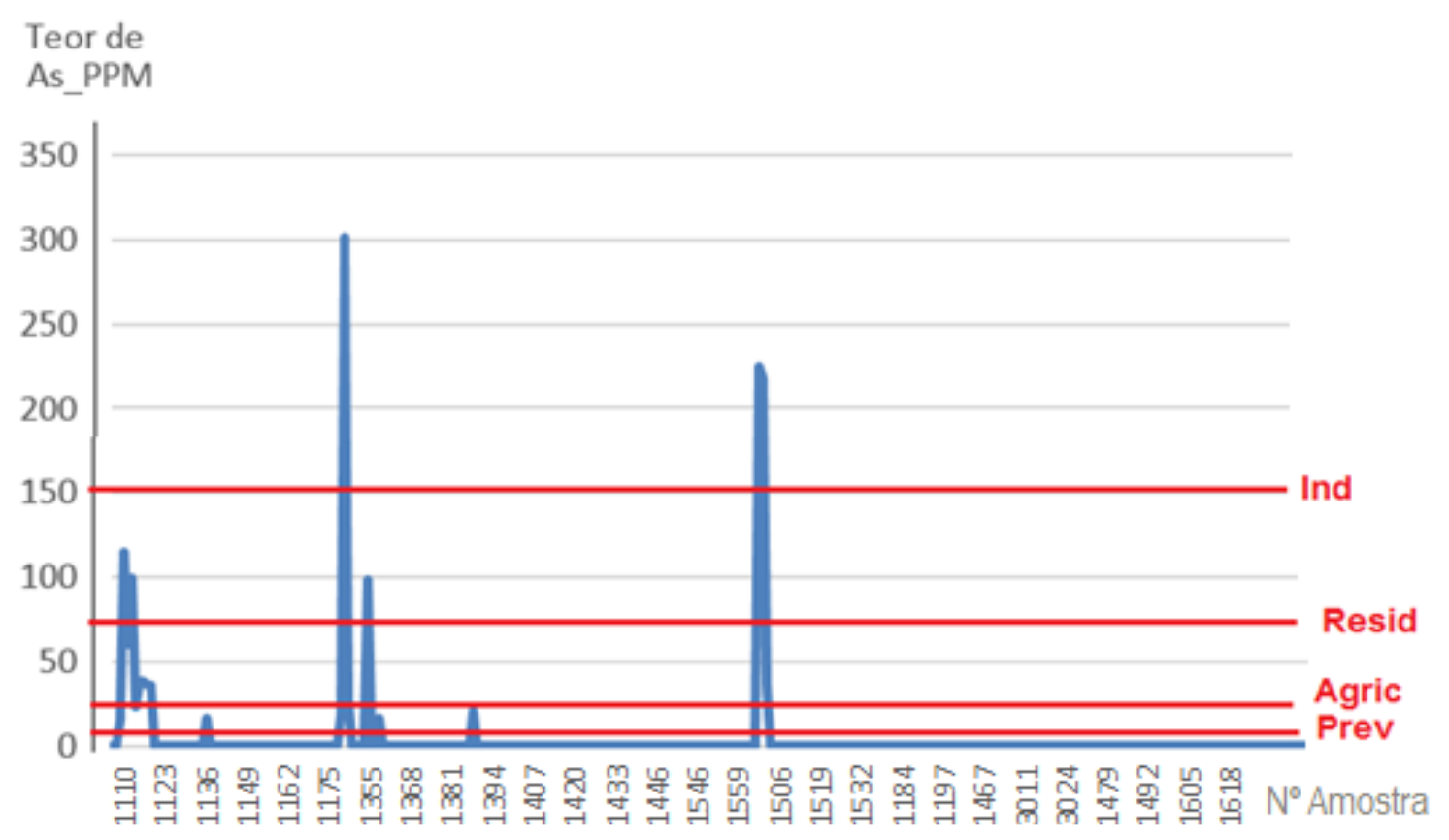

Fonte: CAVALCANTI NETO et al. (2014)

Prev. =Prevenção; Agric. = Agrícola; Resid = Residencial; Ind. = Indústria

As anomalias de Arsênio acima de todos os valores de referência (BRASIL, 2009; SÃO PAULO, 2005 e FLÜCK et al., 2010) estão a montante dos riachos das Várzeas, de Cavalcante e do Angico, além de alguns tributários. Todas elas estão situadas a montante do açude e da sede municipal de São Fernando, além da barragem de Oiticica em construção.

Para a análise de Arsênio em rochas foram coletadas amostras regionalmente e localmente. As anomalias foram determinadas em função da população de dados disponíveis, uma vez que não se tem valores de referências estabelecidos para rochas, de acordo com as normas consultadas. Os resultados analíticos relativos à presença de Arsênio em rocha se encontram sumarizados na tabela 2, juntamente 
com as indicações dos locais onde foram realizadas as coletas. Destaque para o Garimpo Ponta de Serra, cujo Mínimo foi de 58 ppm, para os demais o valor foi irrelevante (zero).

Tabela 2: Síntese estatística dos resultados das análises químicas de rocha para teor de Arsênio (ppm).

\begin{tabular}{c|c|c|c|c}
\hline Locais & Máximo & Média & $\begin{array}{c}\text { Desvio } \\
\text { padrão }\end{array}$ & $\begin{array}{c}\text { Coef. de } \\
\text { variação \% }\end{array}$ \\
\hline Regional & 500 & 14,34 & 61,39 & 428 \\
\hline $\begin{array}{c}\text { Trincheira Ponta } \\
\text { de Serra* }\end{array}$ & 4091 & 17,661 & 31,382 & 178 \\
\hline $\begin{array}{c}\text { Garimpo Ponta } \\
\text { de Serra* }\end{array}$ & 8473 & 617,61 & 573,25 & 93 \\
\hline $\begin{array}{c}\text { Garimpo } \\
\text { Simpático }\end{array}$ & 24 & 0,4244 & 0,791663 & 186,53 \\
\hline $\begin{array}{c}\text { Garimpo Serra } \\
\text { do Rodrigues e }\end{array}$ & 19 & 2,125 & 1,496875 & 70,44 \\
Serra dos Patos & & & & \\
\hline
\end{tabular}

Fonte: CAVALCANTI NETO et al. (2014)

Essas anomalias são aproximadamente coincidentes com aquelas já identificadas pela amostragem de sedimento de corrente, com destaque para os locais onde foram realizadas as atividades de garimpagem de ouro. Essa coincidência espacial indica indubitavelmente que a fonte do Arsênio é o mineral arsenopirita e que a sua mobilidade química é baixa na área estudada, uma vez que sua extensão foi bastante limitada conforme pode ser verificada da comparação dos mapas regionais de sedimento de corrente e rocha.

Os teores de Arsênio, entretanto, são bastante elevados, mostrando que a fonte primária desse contaminante é bastante rica, atingindo valores máximos de 500 ppm (Tabela 2).

As amostras de rochas coletadas nas trincheiras e garimpos apresentam teores máximos de Arsênio mais alarmantes ainda e revelam que as maiores concentrações se situam nos garimpos de Ponta de Serra, Tapera e Anastácio, a montante da cidade de São Fernando, chegando a um valor máximo de 8.473 ppm na área daqueles garimpos (tabela 2). Já nos demais garimpos estudados (o de 
Simpático, o de Serra do Rodrigues e o de Serra dos Patos), os teores foram baixos, com máximo de 24 ppm em Simpático.

Uma única amostra de rocha foi coletada na área do sítio de Encampinado, a Oeste do Garimpo de Tapera, onde se obteve um teor de As de 630 ppm, indicativo de uma anomalia. Esta indicação está respaldada pelos resultados da amostragem litogeoquímica regional e de sedimentos de corrente que apontam para valores mais elevados naquela região. Como não existem atividades de garimpagem nesse local, foi dada pouca importância e coletadas poucas amostras de rochas.

\section{Considerações Finais}

Os teores elevados de Arsênio, elemento químico elencado pela ATSDR (2014) como o mais perigoso à saúde humana, coincide, geograficamente, com os garimpos de ouro de Ponta de Serra, Tapera e Anastácio e com as localidades denominadas de Encampinado e de Sítio Velho, de onde se dispersaram pela rede de drenagem, em direção à sede municipal de São Fernando e a barragem de Oiticica. As concentrações deste elemento estão muito acima daquelas indicadas pela CETESB (SÃO PAULO, 2012 e SÃO PAULO, 2005) e pelo CONAMA (BRASIL, 2009).

Considerando a associação geoquímica do Arsênio e Ouro, recomendamos uma investigação detalhada para verificar a existência da mineralização aurífera nas proximidades de Encampinado, uma vez que os resultados se apresentaram bastante animadores. Todavia, seguindo uma tendência mundial, e caso se confirme a potencialidade, é essencial que o projeto de Mineração contemple os cuidados com esse contaminante.

Por se tratar de uma área de confluência da sub-bacia de drenagem dos Rios Piranhas e Seridó, imediatamente a montante da sede do município de São Fernando, onde encontram-se o açude que abastece a população e sendo o local onde está se construindo a Barragem de Oiticica, existe uma preocupação com possíveis consequências à saúde da população que será assistida pelas águas oriundas deste local. Um estudo detalhado da geodisponibilidade do Arsênio e de outros elementos prejudiciais à saúde humana é indispensável. Essa recomendação permanece, quando se considera a diluição do Arsênio na água que será acumulada pela barragem. 
As rochas hospedeiras deste metaloide, por estarem aflorantes ou cobertas por uma tênue camada de solo, podem contribuir para a dispersão do Arsênio. Essa contribuição apresenta restrições de mobilidade devido ao $\mathrm{pH}$ ácido e é relativamente alto, características desta região do semiárido, inclusive nos sedimentos de corrente e solos exógenos (ex: rejeito dos garimpeiros), resultando numa baixa mobilidade do Arsênio. Por outro lado, é importante mencionar as dificuldades de se analisar este elemento químico, uma vez que pode se volatizar até à temperatura ambiente e os resultados apresentados podem estar subestimados.

Recomenda-se que sejam realizadas, em trabalhos futuros, análises químicas dos elementos da fauna e da flora, especialmente da agricultura e de animais de criação para abate e peixes que serão consumidos pelo homem. Sugerimos também análise da água de dessedentação e o completo estudo da rota de contaminação para verificar se esta rota chega até a comunidade residente na região.

\section{REFERÊNCIAS}

ATSDR (Agency for Toxic Substances and Disease Register) Priority List of Hazardous Substances - CERCLA - Comprehensive Environmental Response, Compensation and Liability Act.U.S. Agency for Toxic Substances and Disease Registry. 2014.

BANCO MUNDIAL. Comunidades e mineração artesanal e de pequena-escala (CASM). Resumo Temático /CASM. Disponível na INTERNET: $<$ http://siteresources.worldbank.org/BRAZILINPOREXTN/Resources/CASMResumoTematic o.pdf acessado em 03/09/2011>. Acesso em 14 de abril de 2011.

BARKER, R. M. Collecting Rocks.U.S. Geological Survey. Information Services. Last modified 06-24-1997. Disponível na INTERNET:

<http://pubs.usgs.gov/gip/collect1/collectgip.html>. Acessado em 17 de março de 2011.

BLOOM, L. Analytical Services and QA/QC. Analytical Solutions Ltd. Prepared for the Society of Exploration Geologists, April 2002.

BOND, W. D. QA/QC Protocols. Quality Assurance and Quality Control Protocols.March, 2008.

BRASIL. MMA. Cons. Nac. Meio Amb. Resolução do CONAMA № 420, de 28 de dezembro de 2009. Dispõe sobre critérios e valores orientadores de qualidade do solo quanto à presença de substâncias químicas e estabelece diretrizes para o gerenciamento ambiental de áreas contaminadas por essas substâncias em decorrência de atividades antrópicas. Publicação Diário Oficial da União № 249, Seção I, de 30 de Dezembro de 2009, p 91-94. 
<http://www.jusbrasil.com.br/topicos/11273591/lei-n-7805-de-18-de-julho-de-1989>

Acessado em 23 de Novembro de 2014.

BRASIL, MMA. A questão da água no Nordeste. Agência Nacional de Águas. Ministério do Meio Ambiente, Centro de Gestão e Estudos Estratégicos. Brasília - DF, 2012.

BRASIL. IBGE. Diretoria de Pesquisas, Coordenação de População e Indicadores Sociais. Estimativa de população 2014. Disponível em http://www.cidades.ibge.gov.br/xtras/perfil.php?lang=\&codmun=240560\&search=rio-grandedo-norte. Acessado em 30 de janeiro de 2014.

BRASIL. Barragem Oiticica. PAC. Min. Planejamento, disponível no site http://www.pac.gov.br/obra/8043, acessado em 15 de março de 2015.

CAVALCANTI NETO, M. T. de O. Geodisponibilidade de metais pesados na área de confluência dos rios Piranhas e Seridó/RN. Tese de Doutorado, 137 pp. UFCG/IFRN, Natal, 18 de dezembro de 2012.

CAVALCANTI NETO, Mário Tavares de O.; FARIAS, Maria Sallydelândia S. de, DANTAS NETO, José. Metais pesados nos sedimentos ativos de corrente na confluência dos rios Piranhas e Seridó, estado do RN. Revista Brasileira de Ciências Ambientais - Número 32, p 112 a 119, Junho de 2014.

DATASUS. Fonte: SIM (SISTEMA DE INFORMAÇÃO EM MORTALIDADE). Situação de base de dados nacional em 14/12/2009. Disponível na INTERNET em http://www.datasus.gov.br. Acessado em 14 de abril de 2011.

FIGUEIREDO, Bernardino Ribeiro; BORBA Ricardo Perobelli; ANGÉLICA Rômulo Simões. Arsênio no Brasil e Exposição Humana. Geologia médica no Brasil: efeitos dos materiais e fatores geológicos na saúde humana, animal e meio ambiente / Cássio Roberto da Silva (Ed.) . [et al.]. - Rio de Janeiro: CPRM - Serviço Geológico do Brasil, 2006.

FLÜCK, R.; CAMPICHE, S.; CHÈVRE, N.; ALENCASTRO, F. DE; FERRARI, B.; SANTIAGO, S. Use of sediment quality criteria for the assessment of sediment toxicity : Applicability to Switzerland. First report in the Project "Assessment of Swiss sediment toxicity”. Centre Suisse d'écotoxicologie appliquée Eawag EPFL. August 2010.

GÓES, Maria Alice C. de; LUZ, Adão Benvindo da; POSSA, Mario Valente. AMOSTRAGEM. Capítulo 2. CETEM (Centro de Tecnologia Mineral) Ministério da Ciência e Tecnologia CT2004-180-00 Comunicação Técnica elaborada para a 4ª Edição do Livro de Tratamento de Minérios, Pág. 19a51, Rio de Janeiro, 2004.

HAMMARSTROM, Jane M.; PIATAK, Nadine M.; SEAL, Robert R. II; BRIGGS, Paul H.; MEIER, Allen L.; and MUZIK, Timothy L. Geochemical Characteristics of TP3 Mine Wastes at the Elizabeth Copper Mine Superfund Site, Orange Co., Vermont. U.S. Department of the Interior. U.S. Geological Survey. Open-File Report 03-431, 2003.

LINS, Carlos Alberto Cavalcanti. Manual Técnico da Área de Geoquímica da CPRM versão 5.0. Min. Minas e Energia. Secretaria de Minas e Metalurgia. CPRM - Serviço Geológico do Brasil. 2003.

MELO, G. D. de. Planejamento dos Recursos Hídricos da Bacia Hidrográfica do Rio Seridó, no Rio Grande do Norte. Dissertação de Mestrado. Programa de Pós-Graduação em Engenharia Sanitária, CT, UFRN, Natal, 2008 
MINAS GERAIS. (RMMG - Rede Meteorológica de Minas Gerais) NORMAS N024 do RMMG. Disponível na INTERNET:

http://www.fiemg.org.br/admin/BibliotecaDeArquivos/lmage. aspx? Imgld=22465\&Tabld=5253 >. Acessado em 20/05/2011.

NOGUEIRA, G.M.F. Conflito e Negociação em Recursos Hídricos: uma abordagem comportamental das decisões. $159 \mathrm{f}$. Tese apresentada ao Programa Institucional de Doutorado Temático em Recursos Naturais da Universidade Federal de Campina Grande UFCG, Campina Grande, 2006.

SÃO PAULO. Decisão de Diretoria № 195-2005- E, de 23 de novembro de 2005. CETESB - Companhia de Tecnologia de Saneamento Ambiental, São Paulo - SP.

SÃO PAULO. Ficha de Informação Toxicológica, Arsênio, 2012. Elaborada pela CETESB - Companhia de Tecnologia de Saneamento Ambiental, São Paulo - SP. Disponível no site http://www.cetesb.sp.gov.br/userfiles/file/laboratorios/fit/Arsênio.pdf. Acessado em 20 de janeiro de 2015.

SILVA, Tarciso Cabral da; SILANS, Alain Passerat de; PEDROSA FILHO, Laudelino de A.; PAIVA, Ana Emilia Duarte B.; BILLIB, Max e BOOCHS, Peter. Planejamento dos Recursos Hídricos na Bacia Hidrográfica do Rio Gramame, Uma Bacia Litorânea do Nordeste Brasileiro. RBRH - Revista Brasileira de Recursos Hídricos, Volume 7, n.4 Out/Dez 2002, 121-134.

UNESP (Universidade do Estado de São Paulo). Museu "Heinz Ebert". http://www.rc.unesp.br/museudpm/banco/sulfetos/arsenopirita.html. Acessado em abril de 2015.

USEPA - U.S. ENVIRONMENTAL PROTECTION AGENCY, EUA.EPA 823-B-95-001. QA/QC Guidance for Sampling and Analysis of Sediments, Water, and Tissues for Dredged Material Evaluations. EUA, 1995.

\section{NOTAS DE AUTOR}

\section{CONTRIBUIÇÃO DE AUTORIA}

Mário Tavares de Oliveira Cavalcanti Neto - Concepção. Coleta de dados. Análise de dados. Elaboração do manuscrito. Aprovação da versão final do trabalho.

Bruna Marcela Soares de Araújo - Elaboração do manuscrito. Análise de dados. Participação ativa na discussão dos resultados. Revisão da versão final do trabalho.

Luiz Fernando Dias Filho - Elaboração do manuscrito. Participação ativa na discussão dos resultados. Revisão da versão final do trabalho.

\section{FINANCIAMENTO}

A São Bento Mineração S/A e sua sucedânea, a Unamgen Mineração e Metalurgia S.A., concederam apoio financeiro ao presente estudo, possibilitando a realização do trabalho de campo, o transporte de amostras e as análises laboratoriais dos níveis de arsênio.

\section{CONSENTIMENTO DE USO DE IMAGEM}

Não se aplica.

\section{APROVAÇÃO DE COMITÊ DE ÉTICA EM PESQUISA}

Não se aplica.

\section{CONFLITO DE INTERESSES}

Não se aplica.

Este artigo está licenciado sob a Licença Creative Commons CC-BY. Com essa licença você pode compartilhar, adaptar, criar para qualquer fim, desde que atribua a autoria da obra. 


\section{HISTÓRICO}

Recebido em: 07-03-2016

Aprovado em: 08-09-2018 